УДК 316

\title{
КЛИПОВОЕ И ЛАТЕРАЛЬНОЕ МЫШЛЕНИЕ КАК ФЕНОМЕН СОВРЕМЕННОСТИ: ТИПЫ МЫШЛЕНИЯ СТУДЕНТОВ БГИТУ
}

\author{
Рудакова Ирина Викторовна \\ к.ф.н., доцент \\ Новикова Нина Геннадьевна \\ ФГБОУ ВО «Брянский государственный \\ инженерно-технологический университет»
}

Аннотация: В статье рассмотрены существующие в исследовательской традиции концепции клипового и латерального типов мышления, дан их подробный анализ. Была предложена модель анкеты для проверки наличия клипового мышления у детей старшего школьного возраста, студентов и представителей молодёжи (от 14 до 25 лет) и представлены результаты проведенного социологического исследования.

Ключевые слова: клиповое мышление, латеральное мышление, креативность, социологическое исследование, молодежь, студенты.

\section{CLIP AND LATERAL THINKING AS A MODERN PHENOMENON: THE TYPES OF THINKING STUDENTS OF THE UNIVERSITY}

\section{Rudakova Irina Viktorovna Novikova Nina Gennadievna}

\begin{abstract}
The article considers the concepts of clip and lateral types of thinking that exist in the research tradition, and provides a detailed analysis of them. A questionnaire model was proposed for testing the presence of clip thinking in high school children, students and young people (from 14 to 25 years old), and the results of a sociological study were presented.

Key words: clip thinking, lateral thinking, creativity, sociological research, youth, students.

Центральное место в жизни человека занимает решение тех или иных задач, возникающих в ходе его деятельности. Помогает индивиду в этом
\end{abstract}


нелёгком труде мышление. Посредством мыслительного процесса формируется как знание, так и субъективное отношение к нему. Притом многие ученые говорят о том, что глубина мыслительного процесса не является данностью от рождения, ее можно развивать, абстрагируясь от стереотипов, стандартов. В современном обществе многие люди мыслят поверхностно, не углубляясь в смысл различных объектов, их свойств. Это не дает возможности принять качественное решение, придумать что-то поистине новое, необычное.

Целью работы является изучение специфики мышления студентов БГИТУ. Ее реализация происходила посредством решения следующих задач:

1. Сравнительный анализ латерального и клипового типов мышления;

2. Создание анкеты для проверки наличия клипового мышления у детей старшего школьного возраста, студентов и представителей молодёжи (от 14 до 25 лет);

3. Анкетирование студентов ВУЗа.

На территории Брянской области такого рода исследование проводится впервые, что позволяет говорить не только о новизне исследования, но и его необходимости.

Термин «латеральное мышление» был введен Э. Боно, который считал, что «данное мышление - нестандартное, боковое, дополняющее логическое мышление человека» [1, с. 10]. Механизм действия такого мышления, состоит из трёх этапов: «1. Выбор фокуса. Для того, чтобы создать нечто новое, яркое, креативное, индивиду необходимо выбрать известную идею (паттерн), от которой он будет отталкиваться... 2. Генерирование латерального разрыва... из некоторой идеи делается определённое смещение, которое нарушит её логику... 3. Установление связи. После действий, выполненных на третьем этапе, человек получает изменённое (чаще всего - абсурдное) суждение, в котором осуществляется поиск чего-то логичного посредством воображения и творчества. В итоге индивид получает совершенно новую идею» [3, с. 92]. Латеральное мышление основано на умении комбинировать, дополнять существующие штампы, то есть фактически он включает в себя перестройку ранее зафиксированных паттернов и провокацию новых.

При этом, в отличие от логического, латеральное мышление характеризуется многовариабельной направленностью, обусловленной тем, что «латеральное мышление оперирует маловероятными подходами, которые в определенный эвристический момент мгновенно приобретают высшую 
вероятность реализации. Исходная точка для рассуждений выбирается произвольной, позволяет делать «скачки» в любом направлении... При получении удовлетворительного результата можно продолжать движение, при отрицательном результате можно осуществить «реверс» к исходной точке и осуществлять поиск в новом направлении» [4, с. 31].

Таким образом, латеральное мышление представляет собой нестандартный вид мыслительного процесса, которому присущи следующие свойства: поиск различных путей решения проблемы, способность выходить за рамки шаблонов, дополняя их, тесно связано с творчеством, мыслительные ходы не всегда могут быть логичны.

Противоположностью латерального является клиповое мышление, которое, прежде всего, характеризуется поверхностностью и фрагментарностью. «Получаемая информация формируется по принципу клипа. Это череда несвязанных между собой, сменяющихся образов, которые подаются зрителю без определенного контекста. Зритель на основе своего жизненного опыта самостоятельно соединяет эти клипы в один контекст, опираясь на собственное восприятие картины мира, находит объяснения, которые его устраивают, совершая при этом ошибки в понимании преподносимой информации» [2, с. 587].

В эпоху информационного общества, человек находится на пересечении непрерывных информационных потоков. Как правило, информация подается в виде ярких, но коротких образов, отсюда, индивид вынужденно «обрабатывает множество обрывистой разнородной информации поверхностно» [5]. В результате многообразия, скорости смены одного образа другим сложно сосредоточиться и сделать более или менее глубокий вывод.

Таким образом, клиповое мышление представляет собой способ мыслительной деятельности посредством короткого яркого образа. Этому мышлению присущи следующие свойства: фрагментарность, поверхностность, отображение клипов без учета какой-либо взаимосвязи, обеспечение эффективного поведения с точки зрения адаптации и выживания.

Клиповое мышление базируется на имеющемся социальном опыте, который, как правило, закрепляется в виде стереотипа. Шаблоны часто используются при возникновении той или иной стандартной ситуации, когда человеку нужно сделать определенный вывод, принять решение. Событие идентифицируется и выбирается наиболее подходящий стереотип, что позволяет не тратить много времени на рассуждения, поиск иного возможного 
решения. Латеральное же мышление, как правило, более глубокое. Оно рассматривает каждую ситуацию в отдельности, ищет ее причины и возможности идентификации без использования стереотипов, посредством чего можно проникнуть в самую суть проблемы, выяснить ее истоки. Притом важным является выяснение того, как воспринимается ситуация в обыденности и определение ее восприятия с нестандартных позиций.

Клиповое мышление базируется на фрагментах информации, часто она не воспринимается целиком. Даже если сам источник информации более содержательный, человек берет лишь определенную часть, которая наиболее проще для восприятия. Все, что за рамками воспринятого фрагмента для человека с клиповым мышлением - лишняя информация, заблуждение, нелогичное заблуждение. В результате делает свои выводы и в последующем оценивает различные события, сопоставляя полученный опыт с их признаками. При клиповом мышлении человек быстро переключается с одной информации на другую, при этом ненужная информация утилизируется для того чтобы снизилась нагрузка на сознание. В результате устранить излишнее перенапряжение. Однако возникает следующая проблема: выводы при клиповом мышлении достаточно быстры, нередко преждевременны, поэтому в них приходится вносить корректировки. Часто клиповое мышление приводит к тому, что изложение его результата происходит на простом языке, не позволяя вычислить наиболее важные свойства объекта, информации.

Латеральное мышление, по сравнению с клиповым, задействует больше информации. Дополнительное количество данных необходимо ввиду того, что в процессе латерального мышления происходит перестройка понятий, знаний, тогда как во время клипового мышления человек просто дополняет или заменяет знания. Большая информативность позволяет выделить больше путей решения проблемы, рассмотреть иные варианты развития ситуации. Возникает возможность продумывания альтернатив, не похожих на стереотипы, стандарты, универсалии. При латеральном мышлении человеку нужно учитывать множество факторов, хранить большой объем информации. Следовательно, мыслительный процесс более интенсивный и углубленный. Выводы здесь более продуманные, охватывают множество сторон объекта. Используемый язык изложения позволяет описать ситуацию, объект в более полной мере, приписать ему свойства, которые сложно проследить без пристального внимания. 
В процессе латерального мышления рождается новая идея, то есть человек способен на основе полученной информации совершить такую перестройку, благодаря которой произойдет наращение новых качеств, видения ситуации, события, объекта, хотя полученные новые свойства вполне могут казаться не всегда уместными. При клиповом мышлении человек не придает новых свойств ситуации, событию, объекту. Он считает, что определенный фрагмент и есть истина без возможности ее изменения. Совпадения фрагмента информации, полученной из любого источника, с устоявшимися признаками в сознании субъекта, достаточно для его идентификации и распознания. Это совпадение, соответственно, задействует и стандартное поведение.

При клиповом мышлении фрагмент воспринимается как устоявшаяся истина. За пределами данной истины лишь заблуждение и лишняя информация, приводящая к ошибкам. Для индивида с развитым латеральным мышлением допущение ошибки возможно. Например, он не всегда уверен, что его решение может качественно изменить объект, ситуацию, однако, одно из предложенных решений способно выявить новые качества объекта, придать ему новые параметры. Для клипово мыслящего субъекта ошибка возвращает его к стандартам, шаблонам, для латерально - повод для поиска новых путей.

Клиповое мышление не заостряет внимание на одной задаче. Оно рассчитано на решение множества задач быстро и без сосредоточения внимания на особенностях одной из них. Информация фрагмента, которая позволяет идентифицировать его как определенную ситуацию по устоявшимся признакам, и подобрать к ней выработанные в практике варианты решений, позволяет быстро переходить от одной задаче к другой. При латеральном мышлении человек сосредотачивается на одной задаче и помимо стандартных ее решений ищет иные способы, внося тем самым вклад в общую практику при успешности их реализации.

Исходя из всего вышеизложенного, можно сделать вывод о том, что латеральное и клиповое мышление имеют различия (табл. 1).

\section{Таблица 1}

\section{Различия латерального и клипового типов мышления}

\begin{tabular}{|c|c|c|}
\hline № & Латеральное мышление & Клиповое мышление \\
\hline 1 & Задействован творческий потенциал & Творческий потенциал не задействован \\
\hline 2 & Формирует новое знание и идеи & Использует готовое знания \\
\hline 3 & Нет стереотипов & Стандарты, стереотипы \\
\hline
\end{tabular}




\begin{tabular}{|c|c|c|}
\hline 4 & Решение более сложных задач & Решение повседневных задач \\
\hline 5 & Нестандартное мышление & Делается упор на социальный опыт \\
\hline 6 & Несколько подходов к решению & Один подход к решению проблемы, но \\
& проблемы, но итог не известен & многообещающий \\
\hline 7 & Задействовано большое количество & Задействовано малое количество \\
& информации & информации \\
\hline
\end{tabular}

Рассмотренные типы мышления имеют общие черты. Следует отметить, что главная общность проявляется в том, что как в латеральном, так и в клиповом мышлении разум фиксирует различные образы. Человек воспринимает различные знаки, символы, которые в определенной степени приобретают различное значение, интерпретируются для последующего использования. Информация воспринимается, формируется в одно целое и затем используется в различных ситуациях. Оба типа мышления имеют схожую структуру. В процессах как первого, так и второго типа мышления человек формирует определённое понятие, суждение и делает окончательное умозаключение.

Таким образом, рабочая гипотеза состоит в том, что у большинства студентов развито клиповое мышление.

Указанная гипотеза определила дизайн исследования и его задачи:

1. Проанализировать, способны ли тестируемые индивиды к закономерному мышлению, сопоставительному анализу, проведению аналогий;

2. Определить уровень оригинальности фантазии, нестандартности мышления;

3. Проанализировать умения разрабатывать четкий план действий в конкретной жизненной ситуации;

4. Определить готов ли человек видеть смыслы в обыденном, или же в его мышлении преобладают стереотипы и готовые образы.

В работе использовались теоретические, количественные и статистические методы научного исследования. Теоретические:

- анализ - было произведено мысленное разграничение подвергаемых исследованию объектов (т.е., латерального и клипового типов мышления), подробно изучены параметры каждого из них; 
- синтез - знания, полученные вследствие применения анализа, были объединены в единую систему, то есть, выделены общие черты двух типов мышления;

- сравнение и классификация - на основании общих знаний о данных типах мышления, выведены их отличительные черты.

Количественным методом работы является анкетирование, главной особенностью которого является развернутость ответов на вопросы (табл. 2). Выборка (364 респондента) формировалась одним из самых точных и надежных методов в социологическом исследовании - путем случайного подбора респондентов. Опрос проходил в face to face режиме, путем случайного выбора студентов. Распределение в выборке по демографическим данным «пол», «курс обучения» соответствует реальному распределению студентов в БГИТУ.

Таблица 2

\section{Образец анкеты}

\begin{tabular}{|c|c|c|}
\hline № & Формулировка вопроса & $\begin{array}{l}\text { Место для } \\
\text { ответа }\end{array}$ \\
\hline \multicolumn{3}{|c|}{1 Логический блок } \\
\hline 1.1 & $\begin{array}{l}\text { Как число } 99 \text { уменьшить в полтора раза, не производя над ним } \\
\text { никаких арифметических действий? }\end{array}$ & \\
\hline 1.2 & $\begin{array}{l}\text { Если четыре дня назад был день, предшествующий субботе, то } \\
\text { какой день будет послезавтра? }\end{array}$ & \\
\hline 1.3 & $\begin{array}{l}\text { Определите, стихотворение какого автора зашифровано при } \\
\text { помощи следующей последовательности цифр: } \\
246381 \\
1161420 \\
151421 \\
14017 .\end{array}$ & \\
\hline \multicolumn{3}{|c|}{2 Творческий блок } \\
\hline 2.1 & $\begin{array}{l}\text { Абстрагируйтесь на время от реальности и представьте будущее, к } \\
\text { котором клавиатура компьютера вытеснила ручку. Как это } \\
\text { произошло? Напишите об этом мини-сочинение (15-20 } \\
\text { предложений) от лица шариковой ручки. }\end{array}$ & \\
\hline \multicolumn{3}{|c|}{ 3 Блок планирования } \\
\hline 3.1 & $\begin{array}{l}\text { Представьте, что вы не можете прожить ни дня без шоколада. Как } \\
\text { вы будете избавляться от этой зависимости? Составьте план. }\end{array}$ & \\
\hline 3.2 & $\begin{array}{l}\text { Вы - студент ВУЗа. Представьте, что до зачётной недели осталось } \\
4 \text { дня, а у вас не доделаны две курсовые работы и } 4 \text { реферата. } \\
\text { Составьте план по исправлению данной ситуации. }\end{array}$ & \\
\hline
\end{tabular}




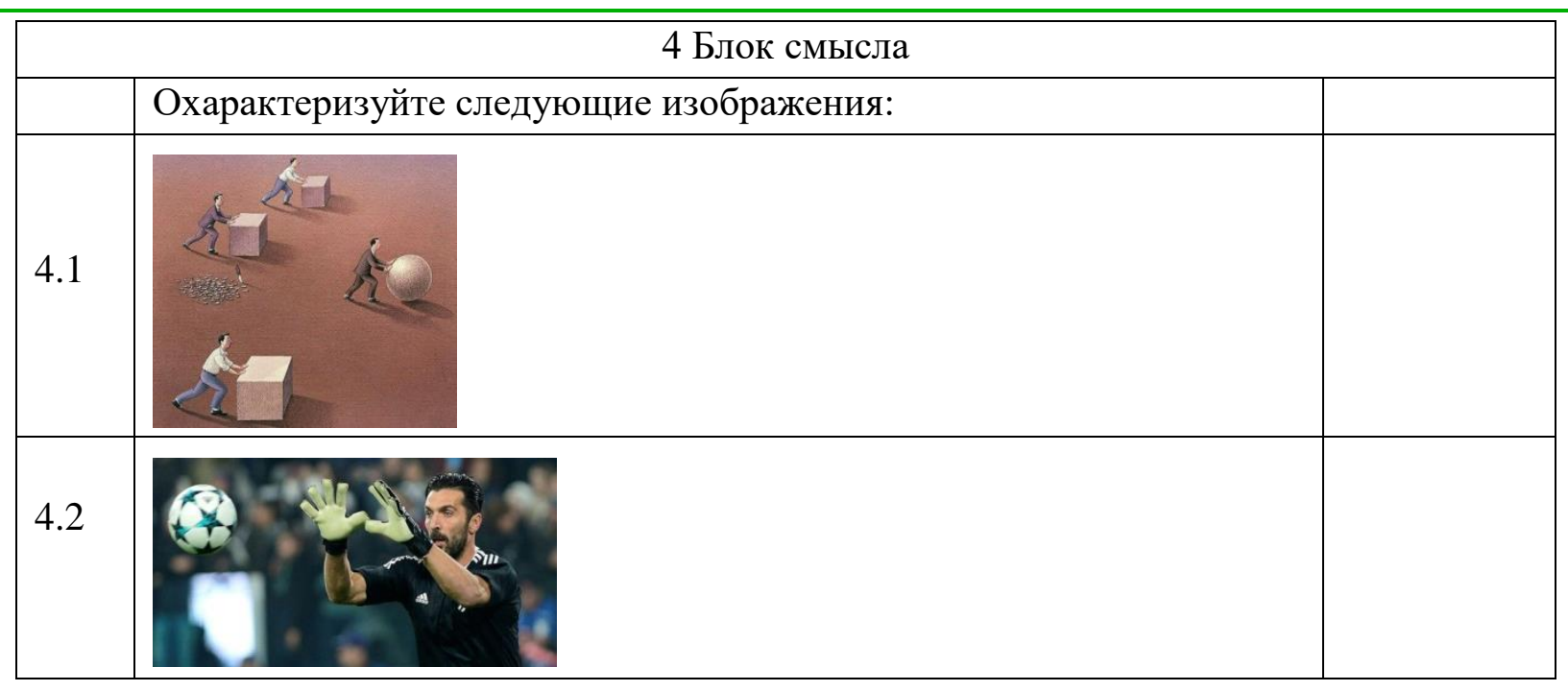

Статистический метод представляет собой систему оценивания созданного анкеты - помимо развернутого анализа каждой работы, респондентам были выставлены баллы за ответ на каждый вопрос (табл. 3).

Таблица 3

Ответы на вопросы анкеты и подведение итогов тестирования

\begin{tabular}{|c|l|}
\hline \multicolumn{1}{|c|}{$\begin{array}{c}\text { № } \\
\text { вопроса }\end{array}$} & \multicolumn{1}{|c|}{ Ответ } \\
\hline 1.1 & $\begin{array}{l}\text { Число 99 надо всего лишь перевернуть «вверх ногами» - получится 66, а это } \\
\text { и есть 99, уменьшенное в полтора раза }\end{array}$ \\
\hline 1.2 & $\begin{array}{l}\text { Перед субботой была пятница. Если 4 дня назад была пятница, то сегодня - } \\
\text { вторник. Если сегодня вторник, значит, послезавтра будет четверг }\end{array}$ \\
\hline $\begin{array}{l}\text { Необходимо сопоставить ритм и ударность цифр, провести аналогию со } \\
\text { знакомыми стихами. } \\
\text { Зашифровано стихотворение В. В. Маяковского: } \\
\text { «..Я } \\
\text { достаю } \\
\text { из широких штанин } \\
\text { дубликатом } \\
\text { бесценного груза. } \\
\text { Читайте } \\
\text { завидуйте } \\
\text { я - } \\
\text { гражданин } \\
\text { Советского Союза...» }\end{array}$ \\
\hline $\begin{array}{l}\text { Ответы должны быть полные, подробные, чтобы можно было отследить ход мыслей } \\
\text { каждого респондента. }\end{array}$ \\
Система оценивания теста балльно-аналитическая: за каждое выполненное задание \\
\hline
\end{tabular}


человек получает определенное количество баллов, и его работа подвергается подробному анализу.

За правильное выполнение блока 1 даётся в сумме 9 баллов ( 1 задание $=3$ балла).

За выполнение задание блока 2 даётся 5 баллов (по шкале от 0 до 5 - в зависимости от степени выполнения).

За блок 3 даётся в сумме 12 баллов (1 задание $=6$ баллов. Оценивание от 0 до 6 в зависимости от выполнения).

Сумма баллов за блок 4 составляет 20 (10 баллов за 1 задание. Шкала от 0 до 10 - в зависимости от выполнения).

0 баллов ставится в случае, если респондент дал неверный ответ (или же

стереотипность преобладает, над оригинальностью), прочерк в ячейке таблицы

свидетельствует о том, что задание было проигнорировано тестируемым человеком.

Максимум за данный тест можно получить в сумме 46 баллов.

\begin{tabular}{|c|l|}
\hline \multicolumn{2}{|c|}{ В конце теста подводятся итоги и оглашаются результаты: } \\
\hline A & $41-46$ баллов - отсутствие признаков клиповости; \\
\hline B & $\begin{array}{l}30-40 \text { баллов - признаки наличия клипового мышления есть, но не ярко } \\
\text { выражены; }\end{array}$ \\
\hline C & $\begin{array}{l}16-29 \text { баллов - признаки клиповости преобладают над оригинальностью } \\
\text { мышления; }\end{array}$ \\
\hline D & $0-15$ баллов - ярко выраженное клиповое мышление. \\
\hline
\end{tabular}

В ходе работы, было проанализировано достаточное количество литературных источников, проведена сравнительная характеристика латерального и клипового типов мышления, отражены их особенности, общие черты, положительные и отрицательные стороны, изучено их применение в повседневной жизни.

На основании информации о типах мышления, был составлен тест, позволяющий определить склонность молодых людей к мышлению стереотипами. Нами была поставлена задача создания теста для проверки наличия клипового мышления у детей старшего школьного возраста, студентов и представителей молодёжи (от 14 до 25 лет) и проверить его.

Исходя из нашей гипотезы, данная проверка включает в себя следующие компоненты:

1. Логический блок, при помощи которого можно понять, способны ли тестируемые индивиды к закономерному мышлению, сопоставительному анализу, проведению аналогий (рис. 1). 


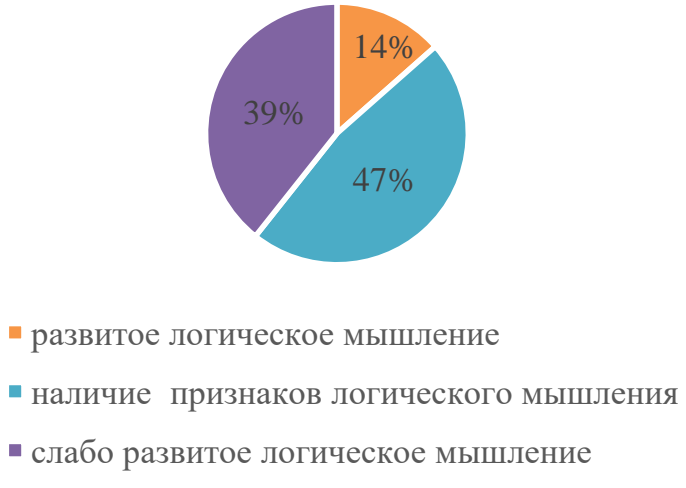

\section{Рис. 1. Результаты логического блока}

2. Творческий блок позволит определить не только уровень интеллектуального развития личности, но и уровень оригинальности фантазии, нестандартности мышления (рис. 2).

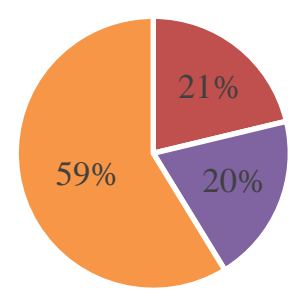

$$
\begin{aligned}
& \text { - ярко выраженые твор.способности } \\
& \text { - средне выраженые твор.способности } \\
& \text { - слабо выраженные твор.способности }
\end{aligned}
$$

\section{Рис. 2. Результаты творческого блока}

3. Блок планирования, главной целью которого является проверка умения разрабатывать четкий план действий в конкретной жизненной ситуации (рис. 3).

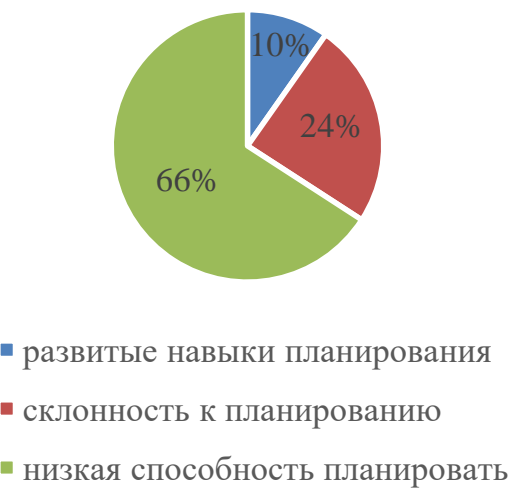

Рис. 3. Результаты блока планирования

498 
4. Блок смысла представляет собой изображения, которые респондентам необходимо охарактеризовать (рис. 4). Таким образом, можно понять, готов ли человек видеть смыслы в обыденном, или же в его мышлении преобладают стереотипы и готовые образы.

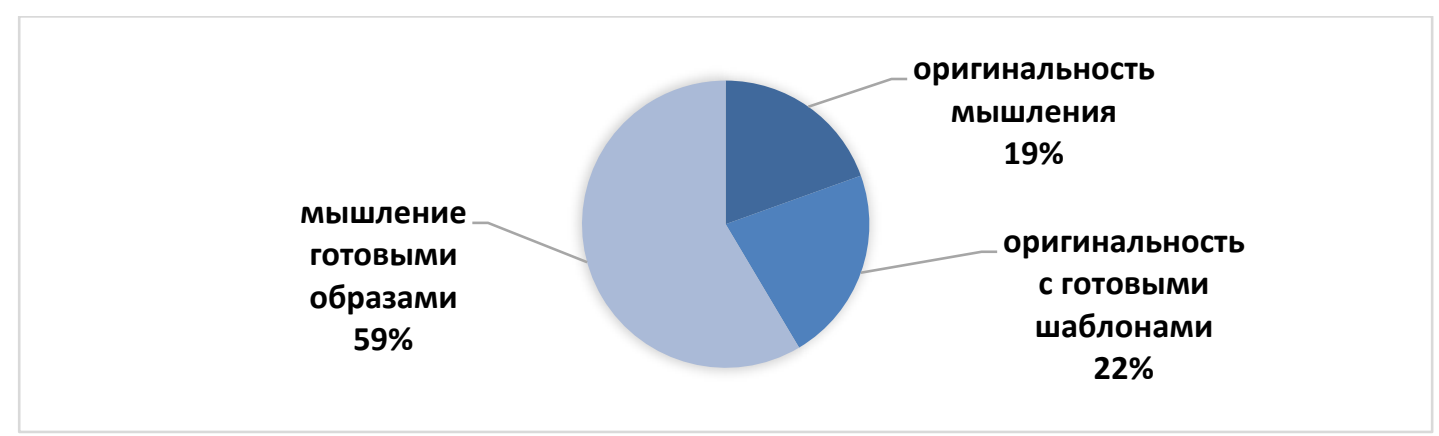

Рис. 4. Результаты блока смысла

В итоге анализ данных в совокупности показал следующие результаты (рис. 5):

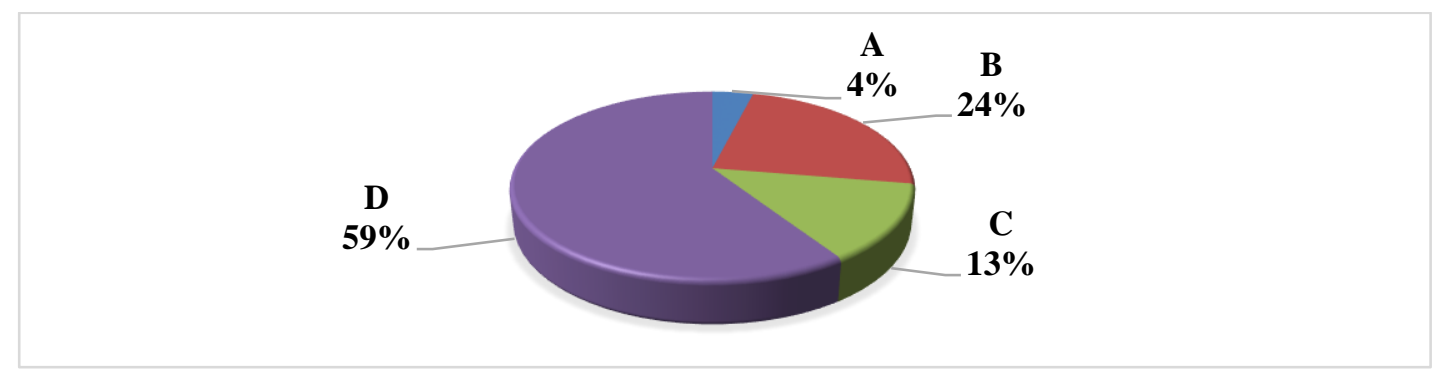

Рис. 5. Совокупные результаты анализа
А) отсутствие признаков клиповости;
В) признаки наличия клипового мышления есть, но не ярко выражены;
C) признаки клиповости преобладают над оригинальностью мышления;
D) ярко выраженное клиповое мышление.

Посредством анализа и сравнения каждой работы можно сделать следующие выводы:

1) малое число опрашиваемых способно к закономерному мышлению, сопоставительному анализу, проведению аналогий;

2) у большинства не только низок уровень логико-математического интеллекта, но и мышление не отличается оригинальностью;

3) большинство респондентов не умеют разрабатывать четкий план действий в конкретной жизненной ситуации;

4) далеко не все готовы видеть новые смыслы в обыденном; 
5) подавляющее большинство респондентов (59\%) показало ярко выраженное клиповое мышление и всего 4\% отсутствие этих признаков.

Остальные $37 \%$ респондентов относятся к смешанному типу, что указывает на их творческий потенциал, который при желании можно развивать.

В целом следует сказать, что латеральное и клиповое мышление нельзя обозначить как нечто худшее или лучшее. Возникает лишь вопрос, способен ли человек в сложной ситуации использовать латеральное мышление, а в более упрощенной для того, чтобы исключить перегрузку и отвлечение на менее важные события, применять клиповое мышление. Данный вопрос может стать основой для масштабных научных исследований. Однозначно можно лишь сказать, что с латеральным мышлением человек не рождается, его вполне возможно развивать. Для этого уже на современном этапе существуют различного рода практикумы, кейсы, задачи. Развитие латерального мышления актуально для творческой профессии, новатора, креативного менеджера и других специализаций, требующих выработки новых подходов, нестандартного видения, актуально и для политических деятелей, обозревателей событий на международной арене.

Однако, если человек не претендует на высокие позиции в обществе, на открывателя новых идей ему вполне приемлемо использование клипового мышления. Особенно это актуально в век интенсивной информатизации, роста коммуникаций, когда растет нагрузка на сознание человека. Клиповое мышление позволяет разгрузить сознание, отсечь излишнюю информацию, выполнять задачи более быстро. Задачу что-то разработать, придумать новый способ решения, к примеру, социальной проблемы, конфликта в трудовой среде, управленческой ситуации следует оставить для латерально мыслящего человека. Его новые идеи затем лягут в перечень стандартов, универсальных решений. Данный перечень будет потом эффективно использован клиптивно мыслящим человеком в рамках высокой многозадачности.

\section{Список литературы}

1. Эдвард де Боно. Латеральное мышление. - Минск: Попурри, 2012. $384 \mathrm{c}$.

2. Бейбутов Д.А., Михайлова Т.Л. Мир как конструкт клипового сознания, или о будущих сценариях человечества // Международный студенческий научный вестник. - 2017. - № 4-4. - С. 585-589. 
3. Котлер Ф., Фернандо де Бес. Латеральный маркетинг: технология поиска революционных идей / Филип Котлер. - М.: Альпина Паблишер, 2010. - $170 \mathrm{c}$.

4. Милехина О.В., Захарова Е.Я. Латеральное мышление как фактор обеспечения успешности работы // Вестник ТГУ. - 2012. - №4. - С. 29-30.

5. Тоффлер Э. Третья волна. - М.: АСТ, 2009. - 800 с. 